\title{
Diagnóstico rural participativo da comunidade de Lavras, Santarém/PA, Amazônia
}

As atividades realizadas por comunidades extrativistas, ainda que não possuam altos níveis tecnológicos, é uma alternativa viável de fonte de renda para essas populações que precisam dos recursos florestais para sobreviver. Portanto, o objetivo do presente estudo foi identificar as principais origens, atividades extrativistas utilizadas como fontes de renda e produtos extrativistas comercializados pela comunidade de Lavras, em Santarém-Pará. Na comunidade, $82 \%$ das famílias são oriundas do Estado do Pará e 12\% do Estado do Ceará, a principal fonte de renda das famílias da comunidade de Lavras é oriunda de aposentadoria pensão e bolsa governamental como Bolsa Família (35\%), os produtos mais cultivados pelas famílias residentes na comunidade de Lavras é o cultivo de laranja ( $20 \%$ das famílias produtoras), mandioca (18\%) e mamão (14\%). Além dos alimentos cultivados, a comunidade comercializa produtos advindos do extrativismo, sendo os principais o óleo de andiroba (23\%), o piquiá (22\%) e a castanha-do-Pará (22\%). Com base nas informações levantadas, é possível que a comunidade estabeleça seus potenciais e fraquezas, contribuindo assim, para melhoria na tomada de decisões visando organização das atividades produtivas e o bem-estar social das famílias.

Palavras-chave: Extrativismo; Floresta; População Tradicional.

\section{Rural diagnosis participative in the community of Lavras, Santarém/PA, Amazônia}

The activities carried out by extractive communities, even though they do not have high technological levels, are a viable alternative of source of income for these populations that need forest resources to survive. Therefore, the objective of the present study was to identify the main origins, extractive activities used as sources of income and extractive products sold by the Lavras community, in Santarém-Pará. In the community, $82 \%$ of families come from the State of Pará and $12 \%$ from the State of Ceará, the main source of income for families in the Lavras community comes from retirement, pension and government grants such as Bolsa Familia (35\%), The most cultivated product by families residing in the Lavras community is the cultivation of orange (20\% of the producing families), cassava (18\%) and papaya (14\%). In addition to cultivated foods, the community sells products from extraction, the main ones being andiroba oil (23\%), piquiá (22\%) and Brazil nuts (22\%). Based on the information collected, it is possible for the community to establish its potentials and weaknesses, thus contributing to improve decision-making aiming at the organization of productive activities and the social well-being of families.

Keywords: Extractivism; Forest; Traditional Population.

Topic: Desenvolvimento, Sustentabilidade e Meio Ambiente

Reviewed anonymously in the process of blind peer
Received: 08/03/2020

Approved: 27/06/2020
Luana Marise Rocha de Sousa

Universidade Federal do Oeste do Pará, Brasi

http://lattes.cnpq.br/1540891277752408

luanamariise.stm@gmail.com

Ana Kaira Canté da Conceição (iD

Universidade Federal do Oeste do Pará, Brasil

http://lattes.cnpq.br/0359544394358895

http://orcid.org/0000-0003-2288-1622

anakaira17@gmail.com

Ádria Giselle dos Santos Lira (iD

Universidade Federal do Oeste do Pará, Brasil

http://lattes.cnpq.br/0436951094856886

http://orcid.org/0000-0002-9711-624X

liraadria971@gmail.com
Mayra Piloni Maestri (iD)

Universidade Federal Rural da Amazônia, Brasil

http://lattes.cnpq.br/2687102042811310

http://orcid.org/0000-0002-8936-952X

mayrapmaestri@hotmail.com

Marina Gabriela Cardoso de Aquino (iD

Universidade do Estado de Santa Catarina, Brasil

http://lattes.cnpq.br/2168843028631934

http://orcid.org/0000-0002-0160-0804

marinaacardosoo@gmail.com
Referencing this:

SOUSA, L. M. R.; CONCEIÇÃO, A. K. C.; LIRA, Á, G. S.; MAESTRI, M. P.; AQUINO, M. G. C.. Diagnóstico rural participativo da comunidade de Lavras, Santarém/PA, Amazônia. Natural Resources, v.10, n.2, p.4448, 2020. DOI: http://doi.org/10.6008/CBPC2237-9290.2020.002.0006 


\section{INTRODUÇÃO}

A agricultura familiar no Brasil, já existia antes mesmo do início da colonização dos portugueses no século XVI, sendo praticada por grupos indígenas que já exerciam atividades agrícolas para a sua própria subsistência no cultivo de roças em meio à floresta (RAMBO et al., 2016). Ao longo do tempo, a agricultura familiar foi desenvolvendo e apresentando características exclusivas, como não possuir área maior do que quatro módulos fiscais, a mão de obra utilizada nas atividades econômicas ser predominantemente familiar e o maior percentual da renda ser obtido das atividades econômicas do estabelecimento (PEREIRA et al., 2017).

Na região Amazônica, a agricultura familiar é uma das atividades mais antigas, identificada pela presença de pequenas propriedades que desempenham seu papel na geração de emprego, renda, diversidade de produtos, e também, contribuem para minimizar o êxodo rural ao criar um elo entre meio ambiente e urbanização, e assim, propiciar o aumento da economia do país por meio da produção de alimentos (BEZERRA et al., 2014).

Neste contexto, o Pará representa $40 \%$ da economia advinda da produção de pequenas às grandes lavouras, com enfoque na agricultura familiar. Em 2013, a área cultivada no Estado atingiu cerca de 1.149.309 hectares obtidos a partir da produção de distintas culturas, gerando um valor de $\mathrm{R} \$ 5,4$ bilhões que equivale a aproximadamente $27 \%$ do Produto Interno Bruto (PIB) agropecuário (ADEPARÁ, 2018). Segundo a fonte, a agricultura familiar é responsável por $84 \%$ da produção de arroz, 83\% de feijão, 82\% de café arábico e $69 \%$ da produção de milho no estado paraense.

Dada a importância dessas comunidades, o objetivo do presente estudo foi identificar as principais origens, atividades extrativistas utilizadas como fontes de renda e produtos extrativistas comercializados pela comunidade de Lavras, em Santarém-Pará. Desta forma, é possível que a comunidade se auto reconheça, estabelecendo seus potenciais e fraquezas, contribuindo, assim, para melhoria na tomada de decisões visando organização das atividades produtivas e o bem-estar social das famílias.

\section{METODOLOGIA}

A pesquisa foi realizada com a participação de 40 famílias da comunidade, as quais se dispuseram a responder um questionário semiestruturado que continha questões referentes à identificação pessoal, características da propriedade, atividade produtiva, valoração e beneficiamento dos produtos cultivados e composição florística da área. Após a obtenção dos dados, as informações foram processadas em planilha eletrônica produzida pela Microsoft e dispostas em gráficos e tabelas para melhor compreensão dos dados. A comunidade de Lavras está localizada no km 19 da rodovia BR 163, no município de Santarém-Pará.

\section{RESULTADOS E DISCUSSÃO}

A comunidade de Lavras é composta por 135 pessoas, correspondendo a 40 famílias, sendo estas oriundas em maioria do Estado do Pará (82\%), seguidas do Estado do Ceará (12\%), conforme mostra o gráfico 
1. No entanto, as pessoas que afirmaram possuir origem paraense afirmaram, em sua maioria, ter descendência cearense. Os grandes motivos destas migrações foram resultado da grande seca e do ciclo da borracha, que se tornou uma rota de escape para estas pessoas que em grande parte eram pequenos agricultores cearenses, corroborando com Rambo (2016), o qual alega que o deslocamento de pequenos agricultores no decorrer da história foi marcado pela procura de uma melhor qualidade de vida e vínculo com a terra.

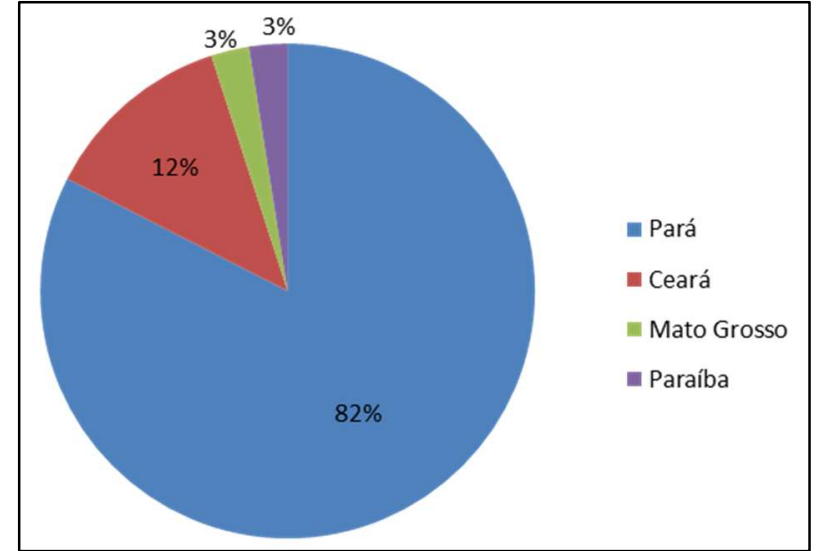

Gráfico 1: Origem das famílias da comunidade de Lavras, por estado.

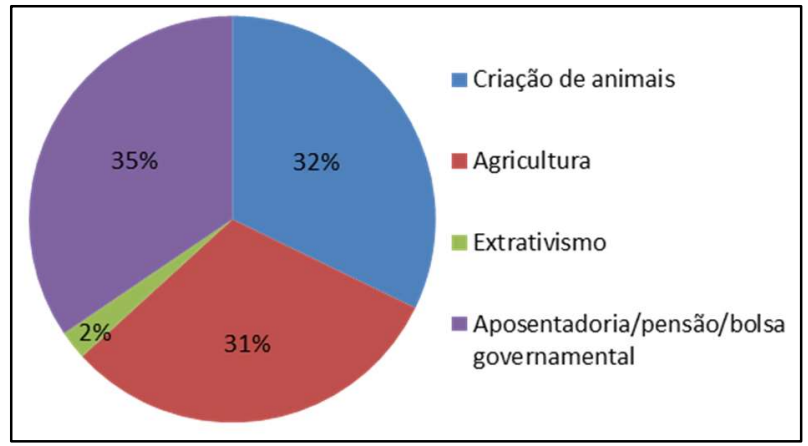

Gráfico 2: Fontes de renda da comunidade de Lavras.

A principal fonte de renda das famílias da comunidade de Lavras é oriunda de aposentadoria, pensão e bolsa governamental como Bolsa Família (recebida por 35\% das famílias), seguida de atividades produtivas representadas por criação de animais (32\%), agricultura (31\%) e extrativismo (2\%), como mostra o gráfico 2. O gráfico 3 apresenta os produtos mais cultivados pelas famílias residentes na comunidade de Lavras, onde podemos observar com maiores destaques o cultivo de laranja ( $20 \%$ das famílias produtoras), mandioca (18\%), mamão (14\%), limão (8\%), maracujá, tangerina e jerimum (6\% cada); coco e açaí (4\% cada), além do cultivo de grãos como feijão e soja ( $2 \%$ cada), cará-roxo, cupuaçu, lima, acerola ( $2 \%$ cada) e produção de hortaliças ( $2 \%$ das famílias).

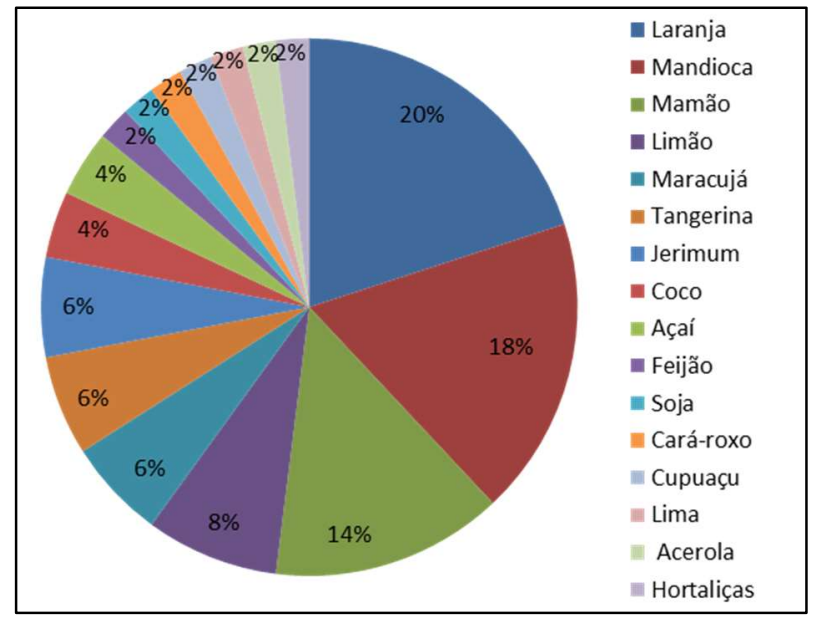

Gráfico 3: Produtos mais cultivados pela comunidade de Lavras.

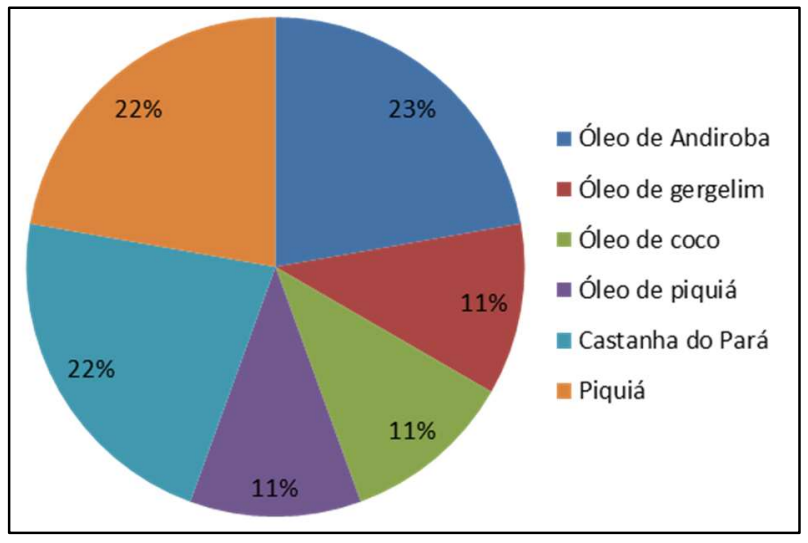

Gráfico 5: Representação dos principais produtos na atividade extrativista da Comunidade de Lavras. 
Todos os alimentos produzidos na comunidade fazem parte do hábito alimentar das famílias e o excedente da produção é vendido na forma in natura nas feiras da cidade (laranja, mamão, limão, tangerina, lima, jerimum, coco, cará-roxo e hortaliças), processados para produção de tapioca, tucupi e farinha (mandioca), vinho (açaí) e polpa de frutas (cupuaçu, acerola e maracujá). A soja produzida é através de arrendamento de terra e não entra na base alimentar dos moradores da comunidade.

Segundo (ADEPARÁ 2018), o Estado do Pará se destaca como um dos maiores produtores de mandioca em nível nacional com 4,7 milhões de toneladas por ano, realizado pela agricultura familiar que contribui na ampliação da economia em pequenas comunidades rurais. Além dos alimentos cultivados, a comunidade comercializa produtos advindos do extrativismo, sendo os principais o óleo de andiroba (23\%), o piquiá (22\%) e a castanha-do-Pará (22\%), como mostra o gráfico 5 . Vários estudos comprovam que a população local possui um amplo conhecimento sobre os recursos naturais, especialmente sobre os diversos usos de espécies vegetais potenciais, bem como uso e manejo adequado da floresta (COSTA et al., 2010).

Em um estudo sobre potencial do extrativismo em comunidades do baixo amazonas, concluíram que grande parte dos entrevistados trabalham em agricultura familiar $(57,5 \%)$, porém não se ocupando somente desta atividade durante todo o ano. Ainda segundo esse estudo, para 35\% dos entrevistados, a principal fonte de renda é a castanha-do-Pará. A Floresta Amazônica não só é fonte de uma rica biodiversidade, como também de uma vasta sociodiversidade, principalmente os grupos indígenas e as comunidades extrativistas, também conhecidos como "povos da floresta", que possuem um valor imensurável para a humanidade, pois portam experiências acumuladas ao longo dos anos quanto ao uso e manejo da floresta e seus recursos associados, contribuindo imensamente para sistemas modernos de manejo ambiental (ELIZABETSKY et al., 1986).

Dessa forma, é indispensável destacar que os benefícios econômicos obtidos das comunidades extrativistas podem ser medidos não só pelos bens que produzem, mas também pelos serviços ecossistêmicos que prestam como a manutenção de processos ecológicos e da biodiversidade, contribuição com locais para pesquisa e educação ambiental, proteção de recursos hídricos (PEARCE et al., 1990).

\section{CONCLUSÕES}

Na comunidade, $82 \%$ das famílias são oriundas do Estado do Pará e 12\% do Estado do Ceará; A principal fonte de renda das famílias da comunidade de Lavras é oriunda de aposentadoria, pensão e bolsa governamental como Bolsa Família (35\%); Os produtos mais cultivados pelas famílias residentes na comunidade de Lavras é o cultivo de laranja ( $20 \%$ das famílias produtoras), mandioca (18\%) e mamão (14\%); Além dos alimentos cultivados, a comunidade comercializa produtos advindos do extrativismo, sendo os principais o óleo de andiroba (23\%), o piquiá (22\%) e a castanha-do-Pará (22\%).

\section{REFERÊNCIAS}

ADEPARÁ. Agência de Defesa Agropecuária do Estado do Pará. Agricultura é responsável por quase $40 \%$ da economia do Pará. Belém: ADEPARÁ, 2018. 
COSTA, J. R.; MITJA, D.. Uso dos recursos vegetais por agricultores familiares de Manacapuru (AM). Acta Amazônica, v.40, n.1, p. 49-58, 2010.

BEZERRA, F. D. S.; LOIOLA, T. O.; MACIEL, R. C. G.; SANTIAGO B. S.. Analise Econômica da Agricultura Familiar na Amazônia Ocidental: Discussões a partir da produção de macaxeira no projeto de assentamento São Pedro/Acre. Revista de Estudos Sociais, Mato Grosso, v.16, n.32, p.3-22, 2014.

ELIZABETSKY, E.; POSEY, D. A.. Pesquisa etnofarmacológica e recursos naturais no Trópico Úmido: o caso dos índios kaiapós do Brasil e suas implicações para a ciência medica. In: SIMPÓSIO DO TRÓPICO ÚMIDO, 1. Anais. Belém: EMBRAPA, 1986.
PEREIRA, G. J.; SCHLINDWEIN, M. M.. Agricultura familiar como geração de renda e desenvolvimento local: uma análise para Dourados, MS, Brasil. Interações, Campo Grande, v.18, n.1, p.3-15, 2017

PEARCE, D. W.; MYERS, N.. Economic values and the environment of Amazonia. London: Macmillan, 1990.

RAMBO, J. R.. Agricultura familiar no Brasil, conceito em construção: trajetória de lutas, história pujante. Revista de Ciências Agroambientais, São Paulo, v.14, n.1, p.86-96, 2016.

A CBPC - Companhia Brasileira de Produção Científica (CNPJ: 11.221.422/0001-03) detém os direitos materiais desta publicação. Os direitos referem-se à publicação do trabalho em qualquer parte do mundo, incluindo os direitos às renovações, expansões e disseminações da contribuição, bem como outros direitos subsidiários. Todos os trabalhos publicados eletronicamente poderão posteriormente ser publicados em coletâneas impressas sob coordenação da Sustenere Publishing, da Companhia Brasileira de Produção Científica e seus parceiros autorizados. Os (as) autores (as) preservam os direitos autorais, mas não têm permissão para a publicação da contribuição em outro meio, impresso ou digital, em português ou em tradução. 